of extremely sharp shadows, is illustrated in Fig. 3, which shows a platinum/carbon replica of an edge of a crystal of methyl orange. It is interesting to note that this shadow was obtained using a target distance of only $2.5 \mathrm{~cm}$. (the distance for evaporated metal is $8-15 \mathrm{~cm}$.), indicating a point source. It will be appreciated that there is a direct relationship between sharpness of shadows and resolution.

The potentialities of the method can be estimated from Fig. 4, which shows a platinum/carbon replica of the surface of a sugar crystal. It can be stated conclusively that the background structure is not due to the granulation of the shadowing material. The reasons are: (1) that the structure varies considerably over the surface ; (2) that diffraction and dark- field tests, applied as a control to each specimen, indicate the total absence of any granularity. A close examination of the original plates shows that this structure consists of minute protrusions some $20 \mathrm{~A}$. in width. This work will be published in grester detail elsewhere.

I wish to thank Dr. J. S. Halliday for his valuable advice, and also Dr. T. E. Allibone, director of the Research Laboratory, Associated Electrical Industries, Ltd., for permission to publish this article.

${ }^{1}$ Williams, R. C., and Wyckoff, R. W. G., J. App. Phys., 17, 23 (1946) . ${ }^{2}$ Bradley, D. E., Brit. J. App. Phys., 5, 65 (1954).

s Heidenreich, R. D., and Peck, V. G., J. App. Phys., 14, 23 (1943).

- Bradley, D. E., Research, 10, 82 (1957).

s Haine, M. E. and Page, R. S., Proc. First European Conf. on Electron Microscopy, Stockholm, 1956, p. 32 .

\title{
PROCESSING OF FOODS WITH IONIZING RADIATIONS
}

$\mathrm{M}$ UCH attention has been aroused in recent years by the possibility of using ionizing radiations in preserving foods. Serious investigations started about ten years ago, although the idea itself is considerably older. While it has been found quite fersible to sterilize foods with radiation, some undesirable changes usually accompany the process. Such changes depend markedly on the way in which the food has been treated, and research has been particularly directed towards finding the precise conditions which give the best products. The possibilities and limitations of the method were discussed at a symposium held at Cambridge during September 26-27. About twenty foreign visitors were among the hundred and twenty who attended, and the two principal British laboratories working in this fieldthe Low Temperature Research Station, Cambridge, and the Technological Irradiation Group, Atomic Energy Research Establishment, Harwell-were represented.

The main attraction in using ionizing radiations to preserve foods is that the amount of radiation energy required to eliminate all food spoilage mieroorganisms raises the temperature of the irradiated food by only a few degrees; the preservation of food in the raw state is therefore possible. A major deterrent, however, is that the associated chemical changes, though small in total quantity, may have adverse effects on the quality of the food, and become evident as changes in the odour, flavour or texture. It is necessary, therefore, to find methods to minimize or mask these quality changes. Smaller amounts of radiation which are insufficient to cause noticeable changes can be used. Such treatments eliminate only a fraction of the micro-organisms present-the socalled pasteurization treatments-and additional treatment, such as heat or refrigeration, is necessary to prevent spoilage of the food due to the growth of the surviving micro-organisms. Some of the results obtained using these techniques were described at the symposium. In addition to these generally applicable methods, there are also uses where small amounts of radiation can be applied to achieve a more limited particular purpose, for example, to eliminate insects in grain or packaged foods, or to inactivate food-poisoning Salmonella organisms in frozen whole egg; these applications, too, were discussed.
Much of the work on the irradiation of foods has been carried out in the United States, and British work is best considered against the background of American investigations. The Quartermaster Corps of the U.S. Army has sponsored the majority of this work and, not unnaturally, much emphasis has been placed upon military uses. The possibilities for civilian applications have, however, been kept clearly in mind. The present state of the work was outlined in two American papers, one by A. W. Harvey, and the other by D. K. Tressler, B. H. Morgan, M. Simon and V. K. Peterson. The dose of radiation necessary to achieve 'commercial' sterility in foods is considered to be in the rangé $3,000,000-6,000,000$ rads. A large number of foods have been examined after doses of this magnitude, and twenty-one have been considered promising. Objectionable flavours are usually found to decrease on cooking, and generally the flavour of the irradiated foods tends to improve after storage for several weeks or months at room temperature. To support the vast amount of laboratory tests being conducted on irradiated foods, extensive animsl feeding tests are in progress. These, so far, have not shown any harmful effects due to irradiation. Limited human feeding tests have also been made, again without showing adverse effects ; and troop feeding tests on a larger scale are planned. To provide adequate food processing and radiation facilities for supplying the necessary food, the U.S. Army intends to construct a food-processing plant equipped with gamma-ray and cathode-ray sources, each of which can treat about 1,000 tons of food per month. Much basic research is being carried out by contract with civilian laboratories. In many cases, where the contractor is interested in civilian applications, the emphasis of this work is on the use of low-dose treatments. The smaller quality changes produced in this way will probably be more acceptable to the domestic consumer, who sees the food at all stages in its preparation for the table.

In Britain also, more attention has been given to pasteurization procedures, since most of the research has been aimed at civilian exploitation. R. S. Hannan described some of the results of a detailed examination of the response of chicken meat towards irradiation under a variety of conditions. With doses of $2,000,000$ rads or more, flavour changes were considered objectionable by most members of a taste panel; 
with lower doses the degree of flavour change depended markedly on the conditions before and during irradiation, for example, its oxygen content, and whether it was frozen. Odour changes in raw minced chicken meat could be detected with doses as low as 50,000 rads, but if such samples were afterwards cooked by steaming most people could only detect adverse flavour changes if the meat had been given doses of 250,000 rads. Whole chicken carcasses responded rather better : after doses of 500,000 rads or more, flavour changes were only just detectable in the roasted birds. Margaret J. Thornley said that bacterial counts on the minced chicken irradiated with 250,000 rads showed that it could be stored at $5^{\circ} \mathrm{C}$. several times longer than unirradiated control samples; lower doses produced only a slight increase in storage life. Whole chicken carcasses, packed in 'Polythene' bags and given 500,000 rads, could be stored at $3^{\circ} \mathrm{C}$. for two to three times as long as control samples. The bacterial flora of irradiated chicken differed considerably from that normally observed. M. Ingram emphasized that selective elimination of some micro-organisms by irradiation could result in the eventual spoilage of the chicken taking an unusual course. Adequate refrigeration seems essential to prevent the growth of possibly harmful bacteria which might survive irradiation.

A number of techniques have been suggested for minimizing the radiation damage to foodstuffs. Thus, for example, a low dose of irradiation combined with some heat treatment may be useful to sterilize foods. Freezing of samples before irradiation usually makes flavour changes less apparent, and the presence or absence of oxygen during and after irradiation is important. The use of such devices is being actively investigated. A very promising approach is to combine radiation with antibiotic treatment. This technique was used by J. Liston and J. M. Shewan in some experiments on the irradiation of fish. Cod and lemon sole suffered little adverse flavour change after doses of 500,000 rads, and the storage properties under refrigeration were improved. A much greater improvement in storage properties was achieved, however, when this dose of radiation was given after the fish had been dipped in a solution of chlortetracycline.

The use of radiation to eliminate a specific harmful micro-organism was discussed in a paper by $\mathbf{R}$. $\mathbf{S}$. Hannan, J. Brooks and Betty C. Hobbs on the irradiation of frozen whole egg. This commodity, large quantities of which are imported into Britain, often contains Salmonella bacteria which cause foodpoisoning. 500,000 rads, given to the egg in the frozen state, eliminates the Salmonella. The principal adverse change was a slight odour in the thawed raw egg, which was not usually detected in baked products made from the egg.

Another promising application is the use of radia. tion to eliminate insect infestation. This is easily achieved by preventing reproduction of the insects with doses up to about 20,000 rads. Two methods of control exist : sterilization of all the insects or swamping of the female population by releasing a large excess of radiation-sterilized males. P. B. Cornwell described some experiments on the elim. ination of grain weevils and flour mill moths, using doses in the range $10,000-20,000$ rads. Direct killing of these insects requires doses about ten times larger than this. If the economics of the process are favourable, there would appear to be little objection to the disinfestation of grain by this method. H. G.
Harvey and R. S. Hannan had examined the effects of low doses of radiation upon packaged foods (for example, ceresls, dried fruits, etc.) to eliminate insects, and found that in nearly all the foods examined, doses of 40,000 rads produced no detectable adverse changes.

The use of radiation in the food industry naturally presupposes that adequate sources of radiation will be available. Not all types of ionizing radiations are suitable. Any which might induce radioactivity in the food would be unacceptable-this excludes neutrons and radiations of energy higher than about $15 \mathrm{MeV}$. Others are excluded because of low penetrating power or high cost. The most generally useful are gamma-rays, of high penetration, and cathode rays, with rather limited powers of penetration. S. Jefferson, speaking on radioactive sources, said that large quantities of fission products will eventually be available for gamma-ray sources. For a number of years, however, cobalt-60, and smaller quentities of cæsium-137, are likely to remain the principal sources. At present the supplies of these are limited. M. C. Crowley-Milling, dealing with electrical machines as sources of radiation, said that cathode-rays of suitable energy are readily obtainable from linear accelerators now manufactured in Great Britain. Against the limited penetration of cathoderays are the advantages of easy focusing, their availability as and when required, and the high dose-rates obtainable. The cost of treatment can be calculated, and Mr. Crowley-Milling gave the following estimates: to treat foods with $1,000,000$ rads costs $0 \cdot 4 d$. per $\mathrm{lb}$.; to treat potatoes with 10,000 rads costs $1 s$. $6 d$. per ton; and to treat grain with 50,000 rads costs 58. per ton. These figures make due allowance for running costs, depreciation, percentage of energy utilization, etc., but do not include any handling costs. The costs of treatment with gamma-rays are more difficult to calculate, but, for some time at least, are likely to be higher than those quoted above. Costs of this magnitude do not appear to be prohibitively high.

Other topics discussed at the symposium included the prevention of sprouting of potatoes (papers from W. G. Burton and D. B. Powell); and, among the less-promising applications, the sterilization of milk (T. Horne), the prevention of mould growth in wrapped baked products (F. J. H. Ottaway), and the elimination of miero-organisms in damp grain (T. A. Oxley).

The intensive investigations of the behaviour of food on irradiation have shown many gaps in the knowledge of how non-irradiated food behaves. This has led to the initiation of much fundamental research, both in academic studies and applied technology. As enzymes are not completely inactivated by the amounts of radiation necessary for sterilization, it is important to know what action surviving enzymes might have on stored foods. The paper by R. Zender, C. Lataste-Dorolle, R. A. Collet, P. Rowinski and R. F. Mouton, of the Battelle Memorial Institute, Geneva, was therefore interesting, dealing as it did with autolytic changes occurring during storage of sterile muscle samples. It may be that some of the changes observed with irradiated meats may be due to autolytic processes rather than to radiation effects. Similarly, much research in radiation chemistry and biology has been stimulated. At the symposium, three papers were presented on radiation chemical aspects (by A. J. Swallow, B. Coleby and N. Uri), and a further paper deait 
with some chemical effects in irradiated meat (G. M. Wilson). These contributions indicated that the theories of radiation chemistry are still far from adequate to explain the changes in such complex systems as foods. As R. S. Hannan pointed out, in nearly all cases, the easiest approach to a particular problem is an experimental one. In the microbiological field there is obviously need for more information on how micro-organisms behave on irradiation, and particularly on the behaviour of those organisms which survive irrodiation. If, ultimately, the idea of processing food with radiation is not exploited, the results of such researches as that of the Quartermaster Corps of the U.S. Army on the properties of packaging materials will be of great value to the food industry.

It will still be necessary to show that irradiated foods are acceptable from the medical point of view, even if the process is considered useful to the food industry and the consumer. To yield information on this topic, animal feeding studies are being conducted at the Wantage Radiation Laboratory, and T. Horne gave details of these, and the plans for future work. The very careful and large-scale experiments being conducted by the Office of the Surgeon General of the U.S. Army should also be extremely valuable. To date, the tests have failed to show any harmful effects through eating irradiated foods. Some destruction of vitamins by irradiation has been noted but, in general, losses are no greater than with most other methods of food processing.

The symposium confirmed the impression that has been growing for some time, that radiation processing is unlikely to displace conventional methods of preservation. It does seem, however, that it will be a useful additional method, and there are clearly some applications of considerable potential use where it has special advantages. But, oven with these, there still remains much more research to be done before the process can be exploited commercially.

A fuller account of this symposium is available on application to the Superintendent, Low Temperature Research Station, Downing Street, Cambridge (L.T.R.S. Memorandum 312).

This article has been prepared as part of the programme of the Food Investigation Organization of the Department of Scientific and Industrial Research.

B. COLEBY

\section{OBITUARIES}

\section{Prof. R. M. Davies}

Rhusrart Morgan Davies, professor of physics in the University College of Wales, Aberystwyth, died suddenly on February 18, a fortnight after his fiftyfifth birthday.

His death terminates one of the most interesting careers in the British university world. $\mathrm{He}$ was a native of the quarrying village of Corris, Merionethshire, and received his early education at the village school and at the grammar school at Dolgelley, where his scientific potentialities were recognized by Dr. John Griffith, one of the most remarkable of Welsh headmasters. In 1921 he entered the College at Aberystwyth, where he was destined to spend virtually the whole of his university career. $\mathrm{He}$ graduated with first-class honours in 1924, and was appointed assistant lecturer in 1925 .

His research career may be said to have commenced at the Admiralty Signal School at Ports. mouth, where he spent the summer of 1925 and where he was introduced to quartz crystals and piezoelectricity. On his appointment to the staff at Aberystwyth he entered upon a research programme on the elastic properties of Rochelle salt erystals, as determined both statically and dynamically. The circuitry of this problem led him to digress, at the instigation of a chemical colleague, into a determination of the absolute dielectric constant of pure benzene at low radio-frequencies; he also developed two types of moisture meter for use with granular materials, one of which was marketed commercially.

These various research projects were pursued with characteristic vigour and determination, and gained him in succession the M.Se. and D.Se. degrees of his University. An opportunity to devote his whole time and energy to research, and in particular to his early field of interest, elasticity, came in 1939 with the award of a Leverhulme Research Fellowship, with which he proceeded to Cambridge to work with Sir Geoffrey Taylor.
Sir Geoffrey soon recognized in him not only one of the few academic physicists interested in the mechanical properties of materials, but also one who was, in addition, gifted with a penetrating mind, experimental skill of a high order, and an infinite capecity for hard work. The association of the two men, started in 1939, persisted through the years; it produced, during the war period, a wealth of results, embodied in official reports, which were of the greatest value in the war effort, both in attack and in defence, and it was later to inspire much of the work of the research school which Davies established at Aberystwyth, whither he returned in 1945 and where he was appointed professor in 1946.

The research work at Aberystwyth was concerned with transient stresses and the propagation of stress waves in solids, and with detonation pressures and shock waves in gases. Much of this work arose from Davies's investigation, carried out in Cambridge and published in the Transactions of the Royal Society in 1948, of the Hopkinson pressure bar, originally devised in 1914 and largely neglected. The resurrection of the pressure bar as a modern instrument of research into transient high-pressure phenomena was typical of Davies's flair for rediscovering nearforgotten techniques; he had read deeply in the classical researches of the past, and nothing gave him more pleasure than to revive, from some forgotten paper by Kelvin or Rayleigh or Reynolds, some argument relevant to a modern problem.

The nature of this extensive research programme, of a type rare in British universities, inevitably brought to Aberystwyth many visitors from many lands, and to Davies himself many invitations to address conferences and symposia, and to join technical committees of various Ministries. In this way he very greatly enlarged his field of activity and became widely known as one of the leading authorities in his particular subject.

In 1956 he was invited to accept a visiting professorship at the California Institute of Technology 